\title{
Seismologists prepare to reap test ban data
}

Washington. Seismologists are set to win unrestricted access to a vast amount of data that will be gathered by a new international seismic monitoring system being established to listen out for nuclear tests under the proposed Comprehensive Test Ban Treaty (CTBT).

Proponents of the treaty hope that it will be agreed this summer. But even if its international ratification takes years, earthquake scientists and others stand to benefit immediately from the plans for open access. Data gathered by a prototype monitoring system from fifty stations worldwide has already been released on the World Wide Web by the Air Force Technical Applications Centre (AFTAC), the US agency with responsibility for nuclear test monitoring.

A panel of the National Research Council, the research arm of the National Academy of Sciences, reported last
November on what was needed to ensure that the treaty's monitoring system will generate the widest possible scientific benefits. Its report, Seismological Research Requirements for a Comprehensive Test Ban Monitoring System, says it will be easy to widen the bandwidth of vibration monitored by the system to include the very low frequencies - down to $0.003 \mathrm{~Hz}$ - of interest to earthquake scientists, as well as the higher frequencies which betray underground nuclear explosions.

The report also called for data from the system to be presented in the Standard for Exchange of Earthquake Data (SEED) format. Thorne Lay of the University of California at Santa Cruz, who chaired the panel, says that many of its recommendations have already been incorporated in the CTBT treaty. Proponents hope the treaty will be signed this summer, and even if ratification is delayed, construction of the monitoring system will begin at that point.

"This is a sea-change, because work that has been classified in the past is going to produce data for the research community around the world," says Lay. The data will not only be twice as voluminous as that currently available, he adds, but will also be available much more quickly to scientists.

The panel also found that an extensive programme of both basic and applied research would be needed to meet the US policy goal of detecting nuclear blasts of as little as 1 kiloton, even if ignited in a cavern to reduce their seismic impact. Such a blast will produce a disturbance of 2.5 on the Richter scale, while existing technology could only identify an explosion of 4.5 , or 100 times the magnitude.

The United States intends to continue secret monitoring for nuclear blasts separately from the proposed international effort.

\section{Change of diet unsettles nutrition research in Germany}

Munich. A DM200-million (US\$140-million) research building owned by Germany's Ministry of Agriculture, and designed to house 600 nutrition researchers, could become a white elephant when completed in 1997 because of a major reorganization of nutrition research in Germany, coupled with sharp funding cuts.

Reflecting pressure on the government to cut public spending and increase the effectiveness of its research budget, the ministry announced plans last August to cut 860 of its 2,600 positions in its five nutrition research centres by the year 2005 . The main opposition, the Social Democratic Party, is now demanding a parliamentary debate, claiming that uncertainty about the ministry's plans for the centres is causing alarm among staff.

The ministry wants to achieve the cuts partly by closing the federal meat research institute (BAFF) in Kulmbach and the equivalent body for corn, potato and fat research (BAGKF) in Lower Saxony. Some of the research from both would be transferred to two broad-based research institutes, in Karlsruhe and Kiel, while the overall target for cuts would be met by placing a ban on new staff at the remaining three centres.

Following strong opposition from the research centres themselves, as well as from the state of Bavaria, in which the BAFF is located, the ministry is now revising its initial proposal. Both the federal government and the researchers involved say that they want a quick decision. But the ministry argues that, as the final plan is tied in with the federal budget proposals for 1997, no decision can be made for several months at the earliest.

The reorganization plans stem from a desire not only to save money but also to deal with long-standing complaints about the inefficiency of the organization of nutrition research in Germany. According to Reinhold Dörre, for example, director of an umbrella organization of scientific societies concerned with agricultural research, much of the work in government laboratories duplicates that carried out elsewhere, such as in universities, while the idea that a

\section{IMAGE UNAVAILABLE FOR COPYRIGHT REASONS}

Feeling the heat? Nutritional research faces staff cuts and other changes in Germany.

research centre should focus on a single food product, such as meat, is outdated.

Ten years ago, already sensitive to such arguments, the ministry endorsed a plan to expand the broader-based Federal Nutrition Research Centre (BFE) in Karlsruhe by expanding its role as an interdisciplinary nutrition research centre, increasing the staff from 250 to 600 and providing a new building for them.

But as the building nears completion, a large question mark stands over its future, partly as a result of further shifts in government policy that have given the Karlsruhe centre a less dominant role in practice. As a result, far from growing in the past decade, staff numbers at the BFE have gradually fallen to 200. "It is all so uncertain", says its director, Ulrich Spieß. "No-one knows what will happen when. And we will be lucky to be left with 160 staff after the cuts."

Spieß would like to share the new building with local university departments in related subjects, bringing the spin-off of mixing basic with applied research. But the ministry is holding its cards close to its chest. A spokesman, Ulrich Metzner, says that the ministry has not made any decision on the building's future, although it is keen not to lose its investment, making it "unlikely that it will agree to share with [any] university".

Meanwhile, despite behind-the-scenes support from Bavaria's prime minister Edmund Stoiber, pressure on agricultural research to rationalize its approach and increase its efficiency means that hopes among the staff of the BAFF and the BAGKF that closure of their institutes can be avoided are probably misplaced.

Indeed, even the Social Democrats, in their demands for a parliamentary debate, are being careful to emphasize that they are seeking an end to uncertainty rather than a reprieve for the threatened research centres.

Furthermore, the federal research minister, Jürgen Rüttgers, told the German Society for Agriculture and Environment Politics last year that agricultural research receives a disproportionately large amount of public research funds. Agriculture contributes less than one per cent of Germany's gross national product, but 2.5 per cent of German research spending goes to agricultural research, he said.

Quirin Schiermeier \& Alison Abbott 